\title{
An Uncertain Dominion: Irish Psychiatry, Methadone, and the Treatment of Opiate Abuse
}

\section{A. Jamie Saris}

(C) Springer Science+Business Media, LLC 2008

\begin{abstract}
This paper investigates some productive ambiguities around the medical administration of methadone in the Republic of Ireland. The tensions surrounding methadone maintenance therapy (MMT) are outlined, as well as the sociohistorical context in which a serious heroin addiction problem in Ireland developed. Irish psychiatry intervened in this situation, during a time of institutional change, debates concerning the nature of addiction, moral panics concerning heroin addiction in Irish society and the recent boom in the Irish economy, known popularly as the Celtic Tiger. A particular history of this sort illuminates how technologies like MMT become cosmopolitan, settling into, while changing, local contexts.
\end{abstract}

Keywords Methadone maintenance therapy - Republic of Ireland ·

Heroin addiction

\section{Introduction}

Although I did not realise it at the time, this paper has its roots in what Fernandez (1986, xi) has called a "revelatory incident" during the course of fieldwork, "a sudden constellation of significances" that yield to an adequate reading only after careful consideration. About three years ago, I attended a meeting of a Research Advisory Group on a project I was leading that looked at prevalence rates of opiate use and abuse in Ireland. One of our tasks was to develop a multiplier for the number of people "in treatment" for heroin addiction. Basically, a multiplier is a number connected to a benchmark (a known number) used to determine "hidden" populations (an unknown number). The Irish government, in short, wanted to know

\footnotetext{
A. J. Saris $(\bowtie)$

Department of Anthropology, National University of Ireland,

Maynooth, Maynooth, Co. Kildare, Ireland

e-mail: ajsaris@eircom.net
} 
the relationship between the people they had "in treatment" for opiate abuse and the population potentially in need of such services. I was leading a team of researchers attempting to answer this question.

I was feeling especially stupid that day (and those who know me well know that I bear such a burden poorly). I had already spent a lot of time trying to find the number of people "in treatment" for opiate abuse, and I had come up against a frustratingly fragmented picture that stubbornly resisted clarification. Inpatient beds could be counted easily enough, but they certainly did not exhaust the definition of, never mind the resources connected to, "treatment." At the same time, my team and I had talked with many people who had a fascination for heroin, many of whom were in receipt of methadone maintenance therapy (MMT), but only a plurality of these folks accepted their (usually) daily dose as "treatment." At the same time, I knew of many non-replacement treatment programmes, some based in secondary and tertiary care facilities, that might be labelled "official," and some well outside them, from more or less formal methods such as Narcotics Anonymous (NA) to something as informal as a basement flat inspected regularly by a concerned aunt, that ex-addicts swore were central in their going (and staying) "clean." "Treatment," then, was one of the semantically slipperiest of the terms that we encountered during the course of this research. Who, then, could tell me how many people were "in treatment," which, after all, was central to completing a task for which the Irish government had given me some support? After much conversation, one of the group, a psychiatrist who was professionally involved in setting treatment policy at a national level, grudgingly admitted that the only number that was available to use as a treatment benchmark for this study was the Central Treatment List, that is, the list of people legally being prescribed methadone. The ethnographer in me wailed in protest at this bizarre reification, but the other part of me, the PI of a project needing to provide some useful information to policymakers, tried to make the best of the situation.

I will admit that this attempt to fuse the sorts of things that interest me as an anthropologist and the sorts of things that might prove useful for policymakers (while being ethically consistent throughout) has been of only mixed success. The journey, however, has led me to reflect seriously on the various scholarly, technical and political currents that define the problem of heroin use, and its treatment in Ireland: particularly, how my two main research concerns over the past decade or so-Irish psychiatry, on the one hand, and forms of structural violence in Irish society, on the other-might relate to one another. Part of this interest is in the form of a quandary, that is, thinking about the reason for the hesitancy of Irish psychiatry, institutionally, to see drug addiction in general and heroin abuse in particular as a logical market for its services. Psychiatry in Ireland has only tentatively experimented with different models of methadone distribution, during a decade when heroin use has increased substantially in Ireland, this despite methadone's being a highly psycho-active substance, prescribed routinely for a psycho-social problem. The second strand in my argument may strike some readers as both oddsounding and disconnected from the first strand, but I hope the idea improves upon acquaintance. I will state it as starkly as possible, then qualify it as I go on. Despite surface appearances, MMT is only tangentially connected to heroin use and abuse. Instead, from the beginning, it was aimed at the behaviour of addicts. This 
seemingly minor reconceptualisation makes for some significant shifts in thinking through the history and current location of MMT in various cultural settings. Examining treatment in this way and in one context, I argue, socially and culturally situates a cosmopolitan technology, even while highlighting certain general features in local professional environments implicated in the increasing "therapeutisation" of everyday life. In pursuit of this goal, I provide less a narrative of the reasons why psychiatry failed to decisively "take over" opiate abuse in Ireland and more a map of how several local and cosmopolitan discourses and sets of practices around the social recognition of the heroin user-such as medical subject, moral problem, public health dilemma, potential criminal threat, policy object and subject of governance-interacted with one another over the course of a quarter-century in Ireland.

\section{The Uses of Methadone}

Any acquaintance with state bureaucracy will throw up the sort of almost-principled Kafka-esque ambiguity of the meeting I sketched out above. Thus, the complex semantics of the situation (in other words, what "treatment" meant to different people in this research) interested me as a fieldwork question, but did not strike me as theoretically critical. By the time of this meeting, for example, my team and I had already spent some months researching methadone, and its social life had already struck me as productively complex. Green and Brown "phy" (Physeptone) was a common feature of my and my colleagues' interactions with people using gear (heroin). It emerged at odd points in the work. I had the disturbing experience, for example, of talking to folks with children who would never think of leaving gear out in the open, but who would have a large bottle of methadone (sans child cap) next to the kitchen sink. This sugary syrup contained enough opiate to, in theory, kill every non-addict in the house, but in a categorical alchemy worthy of investigation by Benjamin Whorf, its status as "medicine" allowed it to stay out in plain sight, in opposition to "illegal street drug," which needed to stay hidden. We also knew (and most therapists we knew agreed) that a significant number of folks on the Central Treatment List (about 30\%) (see Cullen et al. 2000) were taking heroin at the same time as methadone, simply avoiding the inspectorial regime of urine samples or actively subverting it by slipping "clean" samples to General Assistants who were, to be kind, less than motivated to watch terribly closely as someone urinated into a vial. Statistically, this made the List's status as a benchmark very problematic, as benchmarks and multipliers are not supposed to overlap. To put it another way, a significant amount of "hidden" heroin use was, in fact, "hiding" on the list itself. At the same time, we also knew of a lively street trade in methadone, which I was already trying to connect to various "styles" of opiate use that I thought we were observing. These included people who felt that their usage was getting out of control

\footnotetext{
${ }^{1}$ Pronounced in most Dublin-English dialects as "phoy." It is striking how dominant this term is, eclipsing the general use of "methadone" or any other description. The only exception is that some addicts separate phoy (brown) from methadone (green) as different medicines (see O'Toole 2005, p. 77).
} 
but who were, for whatever reason, unwilling to go into formal "treatment." Thus, we discovered hidden heroin use on the Central Treatment List and illegal therapeutic use of methadone outside of it.

Even more challenging to understand was the brute fact that much of what methadone "did" in our experience was clearly non-chemical. It was certainly like heroin in this respect (see Saris and Bartley 1999a). The schedule of dosing that the state demanded, for example, was at least as important as its physiological effects for many addicts. To the good, this dosing can become a part of the daily routine: going to the clinic, meeting with whomever is there, taking the methadone and giving urine samples became a necessary bridge to sorting out general issues that needed sorting — such as getting a TV license, managing medical cards or housing difficulties, dealing with general medical issues and getting counselling about problems at home. While methadone was the obvious reason why clients called at a particular clinic, then, the visit made available other services that were often legitimately seen to be more pressing in the daily scheme of someone's life than a deracinated sense of "addiction."

On the other hand, it was clear from the work of much of the team that coming to a clinic regularly also posed significant challenges for other addicts. Pretty much everyone you meet in the queue to give a sample of urine, or to get a script, at a clinic is an expert at procuring illegal substances, thus, these visits are great situations in which to make connections and "score," that is, obtain drugs. Of course, the staff at these places know perfectly well that people sometimes "hook up" (meet) with each other at the clinic and head off for the day together for precisely this purpose. People who have been scripted out to pharmacies or general practitioners (GPs) in the community, for example, will still often appear at the clinic even though they are not supposed to do so. In other words, just as hospitals are very good places to get serious infections, so, too, are drug clinics great places to lay the groundwork for scoring whatever happens to suit your pharmacological fancies.

It is this relationship between social complexity and policy ambiguity around methadone that strikes me as singularly productive. As Agar and others have pointed out, methadone exists as both medicine and substitute addiction-a close relative of "dirty" dope and an often necessary step towards "clean" sobriety (Agar and Reisinger 2001, 2002a, b). Nearly every heroin user knows where to buy it illegally, but it is the main pillar of most state treatment strategies. In MMT, then, we have a necessary benchmark for policy whose social existence renders it statistically problematic to use as a source of informing policy. Ironically, however, its availability on the street is often a self-treatment step for individuals trying to control their spiralling gear habit and, therefore, can sometimes serve as a bridge into more formal treatment options. Finally, a lot of what methadone "does" is incidental to its pharmacological effects - the rites of institution (in Bourdieu's apt phrasing) that surround its distribution are important in stabilizing some addicts, even as they provoke resistances in others, making them more likely to fall off the treatment wagon.

Methadone's use also highlights some of the pitfalls for psychiatry in the popular success of some of its ideas, as well as just how important it is to understand local 
inflections when discussing the psychiatrisation of a "society." In the United States, for example, MMT became the standard for heroin addiction treatment in New York but faced a much more difficult time in other parts of the country. On the face of it, there is much to support a positive evaluation of MMT, based on an extensive body of international literature demonstrating the positive effects of methadone maintenance treatment on a range of associated problems, including illicit opiate use and frequency of injecting and sharing needles, amongst other risk behaviours, drug-related crime and even mental and physical health status and social dysfunction (Gossop et al. 1998; Marsch 1998). Also, it is a pretty inexpensive treatment option. Yet, methadone is not an especially safe drug. Steentoft et al. 2006, for example, found that methadone had killed more people than heroin in Denmark in 2002. Very few people, moreover, are really resigned to the permanent ingestion of an opiate, neither the users themselves nor the tax-payers who fund such treatment (for a recent critical, but well-considered look at long-term methadone use, see Michael Negroponte's Methodonia [2005]). Nonetheless, no state treatment regimen, at least in Europe (the situation is more variegated in the United States), can imagine "tackling" heroin addiction without it (e.g., Drugs in Focus 2002).

\section{Methadone and Psychiatry}

It seems to me that the best way of dealing with these complexities, at least in one national infrastructure, is moving our lens out a bit to capture some of the wider processes of which methadone use in Ireland is a part. Then, we can refocus back down to the level of a particular national history of the relationship of psychiatry to the treatment of drug abuse by looking at the introduction of methadone in Ireland.

Although it is not generally appreciated, in the history of psychiatry, methadone is one of the earliest and certainly amongst the most successful refigurings of a specific psycho-social problem, heroin addiction, which had hitherto been unproblematically located in the "mind" (that is, a deficit in "will," potentially accessible to a "talking cure"), into one situated in the brain (or its chemical dynamics), best approached through pharmacological intervention. Put in this way (and given the time frame of the early trials of the pharmacological treatment of heroin addiction in the late 1950s and early 1960s), therefore, MMT can be located historically and culturally in an important move of psychiatrically influenced ideas away from their traditional institutional settings and into the warp and weft of everyday life. As I detail below, its discovery by Dole and Nyswander, particularly their interesting understanding of a "metabolic lesion" for which methadone provides a very safe work-around, effectively establishes the paradigm for what we might call the current pharmacological imaginary of human mental, emotional, and behavioural ills- that is, an initially occult disorder in the dynamics of body chemistry, that a drug provides both a relief for and a theoretical model of those dynamics. It is no surprise, then, that a quarter-century after the clinical success of methadone, postdocs from Dole's lab were applying this idea of a metabolic lesion with much better genetic and pharmacological techniques (and with an eye to a 
much larger potential market $)^{2}$ to issues like obesity only 20 years after the official coining of this concept (Dole and Nyswander 1967).

The key texts in this movement, as scholars such as Agar and Courtwright have pointed out, are an article published by Dole and Nyswander in 1967 and its followup in 1976. In these pieces, the authors state expressly what had only been implied in their previous work. Heroin addiction, they argue, is the result of a deeper metabolic disease that potentially can be stabilised through pharmacological intervention. Methadone, an opiate agonist, operates basically by getting to the mu opiate receptor ahead of heroin and, consequently, blocking the euphoric qualities associated with this drug. While lacking the euphoric qualities of heroin, it still manages to bridge the need for the illegal drug. Without such a work-around, the authors argue, the various sticks in an addict's life-from the social risk associated with illegal use to the actual physical dangers that surround the economic activity to pay for such use-simply did not serve as sufficient deterrent to ingesting heroin. The prototype of urban failure, the junkie, then, could be redefined as a sufferer with an unfortunately altered biochemistry. As Agar and Reisinger put it,"'Dope' became 'medication,' the 'addict' became a 'patient,' and 'addiction' became 'treatment'" (1971, p. 176). Methadone is, arguably, more physically addictive than that for which it substitutes, but because it is so well tolerated, while it stimulates opiate receptors to the point where heroin's pleasure is supposedly removed, its action is seen to be a fair exchange between treatment and side effect. Many former addicts credit methadone with saving their lives; many others are profoundly dissatisfied with the substitution of "one addiction for another" (see Negroponte 2005 for a critical view of New York City's methadone policy).

Nonetheless, the authors are fairly defensive in these otherwise celebratory pieces. They bewail, for example, the hesitancy with which this (what they see as a safe, powerful, and cost-effective) treatment has been taken up. They place the blame for both the slowness of its acceptance in many parts of the country and some of the social complexities around providing addicts MMT to police hostility towards the population they are trying to help and political malfeasance in the broader society. By the 1990s, methadone was under even heavier pressure-from different replacement therapies, on the one hand, to a stronger abstinence orientation in some drug treatment regimes, on the other. Still, Dole, ${ }^{3}$ now a sort of eminence grise in metabolic chemistry and psychopharmacology, has steadfastly refused to see his discovery in anything but the most positive light, even questioning the widespread leaking out of this drug for illegal purchase (see Dole 1991, 1996).

\footnotetext{
${ }^{2}$ Corporate pharmacological interest in addiction has grown apace with the increasingly variable relationships "addiction" can form with people—from specific psychoactive substances, such as alcohol and heroin, to strongly rewarding activities, like gambling and sex, to "real" rather than metaphoric hunger, that is, excessive eating leading to obesity. From the 1980s, of course, the cause for this hunger has been the "Holy Grail" of this research. The hope that there might be something "like methadone" to deal with such hunger has produced a veritable tradition of research, genealogically connected to Dole's Lab at Rockefeller University (see Shell 2003).

${ }^{3}$ Nyswander died of lung cancer in 1989. She was a chain smoker who, despite her best effort, was unable to quit. Courtwright (1997), in a provocative analysis connecting healers and syndromes, suggests that her own nicotine dependency sensitised her to her patients' issues and "prepared" her to accept the notion of a metabolic lesion best treated through long-term maintenance therapy.
} 
Dole and Nyswander, however, while arguing heuristically for the effectiveness of MMT, produced a then-radical model of the underlying reason for heroin addiction, which was both elegant and opaque at the same time (Courtwright 1997). They claimed that heroin addiction caused a "metabolic lesion," a permanent biochemical change in the addict, resulting in a permanent biological need for narcotics. Implicitly, this was based on another idea that was to become increasingly important in both psychiatry and the popular consciousness thereof, that is, "predisposition." Clearly, some, but not all, metabolisms were "lesionprone" for opiates, preparing a user for the recognised social state of "junkie." If correct, then, MMT was less a cure than a sort of metabolic holding pattern, but one based on a radical re-theorisation of the will. It follows, therefore, that addicts would likely require methadone for the rest of their lives, much like diabetics would need insulin: hence the term "maintenance." Although methadone often had been (and still is) used as a method of detoxification, with a gradually diminished dosage leading to total withdrawal, Dole and Nyswander claimed that the high rate of return to heroin addiction proved that detoxification remained difficult and that, therefore, their metabolic theory was evidence-based (for a popular critique, see Biskind 1975).

\section{Psychiatry and Culture}

When put in this way, then, MMT can be seen as an early confirmation of the vision of progressive psychiatric theorists in the mid-20th century, who predicted, and looked forward to, the continuing therapeutisation of everyday life. At least in North America and Europe, psychiatric expertise has blended with increasing pharmaceutical virtuosity (and the proliferation of pharmaceutical marketing techniques) such that a variety of conditions is now approachable as psycho-medical issues: issues that only a generation before might have been seen as unfortunate consequences of living, or merely as the result of poor individual choices. Indeed, many of these newer conditions make a mockery of the mind-body duality that was so important in both the development of the Neo-Freudian instantiation of a psychiatric hubris and its deflation in the 20th century (Rieff 1987). We seem to be, in short, in a psycho-medical moment, where psychiatry's "biologisation" has been coterminus with the persuasiveness of a psycho-social argument justifying the treatment of conditions, such as moderate erectile dysfunction amongst males over the age of 65 , whose "medical" status would certainly have been questionable only a decade or so earlier.

Perhaps the greatest success of these interlocking discourses, as well as the site of their most obvious convolutions and evident contradictions, therefore, occurs in the phenomenon of addiction. The surrendering of autonomy and self-determination to a substance, possessed of no agency of its own, looks like the most evident example of fetishisation and alienation, all the more difficult to understand, as the effects of the most commonly addictive drugs have been well-known in our culture for at least centuries, if not millennia (Devereux 1997). Furthermore, rueful reflection on this self-inflicted enslavement to a thing has a long history in Western thought, so much 
so that such works can almost be discussed as a genre. Addiction, for example, can be constructed as a sort of replaying of the Fall, but with the added bonus that the torments of Hell get to be experienced in this lifetime (such as De Quincey 1822), or as a Dionysian escape from the conformity enforced by bourgeois society (Burroughs 2005), or, even as a means of coming, with some suffering, to a sense of mature enlightenment (such as Marlowe 1999).

By the mid-20th century, though, any "moral" interpretation of addiction was facing serious competition from more "physical" readings. In some ways, then, the success of the Alcoholics Anonymous model during this same period, generally seen as evidence for strength of public Protestant culture in the United States (Woolverton 1983), might have been more a harbinger of its needing to make room for significant competition. By the second quarter of the 20th century, for example, various paradigms dominant in psychiatry and psychology had begun to see addiction as an obvious target for their intervention. A Soviet model, for example, was already expressly biological, based on operant conditioning (Rieff 1987; Wortis 1950), and other national traditions were vigorously experimenting with a variety of physical methods.

Methadone, though, scored the most unqualified success in this respect. This success has produced an important, but largely under-appreciated, refiguring of Mind/Body issues very much in line with Dole and Nyswander's formulation. Dole and Nyswander's reading of how methadone was effective (that is, a sort of invisible lesion to which certain people were "predisposed" clearly opened up the possibility of non-substance addictions, such as gambling and sex). These connections can be traced in the careers of professional scientists who got their start at the Rockefeller University Lab responsible for MMT to the now common-sense and, therefore, rarely attributed, constructions of how "addiction" works.

Interestingly, "addiction" develops an ever-greater currency in a variety of discourses ${ }^{4}$ a bit earlier, but in roughly the same way that "culture" wanders away from anthropology. Early ethnographic work on addicts, for example, treated heroin users as a sort of internal exotic "tribe" and a part of "home" that could be illuminated through this otherwise "away" methodology. Similarly, addiction saw its originally quite circumscribed ambit in psychiatry expand, generally from alcohol and a limited number of other drugs, increasingly to behaviour, from

\footnotetext{
${ }^{4}$ I think that aspects of these issues bear on debates in psychiatric anthropology and the anthropology of psychiatry, especially in the United States. Tanya Luhrmann (2000), for example, argues cogently for a particular split in American psychiatry: that it is in "two minds" about the subjectivities of the clients with whom they interact. Echoing earlier debates among American psychiatrists (e.g., Eisenberg 2000) about the replacement of brainlessness with mindlessness in psychiatric theory, she is predisposed to shy away from their evident connections. They are, for example, both techniques and technologies of transformation, on the one hand, and "machines," in Deleuze's sense, that recode meanings, according to dominant logics, on the other. The more recent "biologisation" of psychiatry, in the sense of the triumph of pharmacological interventions at the expense of various "talking therapies," seems to me to provide merely different methodologies connected to the same professional project of transformation. In Nyswander's case, for example, these merged seamlessly over the course of one therapeutic career. It was her dissatisfaction with various forms of "talk therapy" to meaningfully change the behaviour associated with addiction to heroin that encouraged her to experiment with pharmacological means towards the same end (for a similar critique with respect to depression, see Metzl 2003).
} 
excessive gambling to promiscuous sex, that would have been seen as simply abnormal or immoral before. Only a little later, "culture" became increasingly connected to novel setting (such as organisations) and, indeed, to certain internal exotics, like "addicts" who are presumed to share entire lifeways around the ingestion of their substance. In this sense, then, there is an "after-addiction" moment in popular thinking, much like there is an "after-moment" for the Boasian synthesis of culture(s) (lowercase and potentially plural). Now, of course, one can be addicted to nearly anything, and different groups of such addicts are presumed to constitute a sort of tribe in our midst, with shared, albeit unusual, values, and often occult ways of spotting one another, and therefore are available to the anthropological and broader social science imaginary in novel ways.

\section{Irish Psychiatry and MMT}

When ideas like "metabolic lesion" and techniques such as MMT become truly cosmopolitan, however, they settle into certain institutional landscapes at particular historical moments, as various culture-histories of psychiatry have taught us (e.g., Lakoff 2006; Sadowsky 1999; Saris 1996, 1997, 1999). Irish psychiatry's reaction to drug addiction in general, and heroin abuse in particular, is a case in point (Fig. 1). In general, Ireland has tracked the system in Britain, developing a central treatment agency established at Jervis Street in Dublin in the 1980s, under the clinical direction of a consultant psychiatrist. It was based on an abstinence model, alongside criminalisation of heroin and addicts. In 1988, following the closure of Jervis Street clinic, the National Treatment and Rehabilitation Board (NTRB), widely know as "Trinity Court," moved to Pearse Street. This was another psychiatrically directed facility (O'Reilly et al. 2005), all of whose consultants had spent time training in the United Kingdom and United States. Over the next decade, however, services and policy changed from a service that was centralised and specialised, with an ideology tending towards abstinence, to the institutionalisation of regulated methadone prescription by GPs.

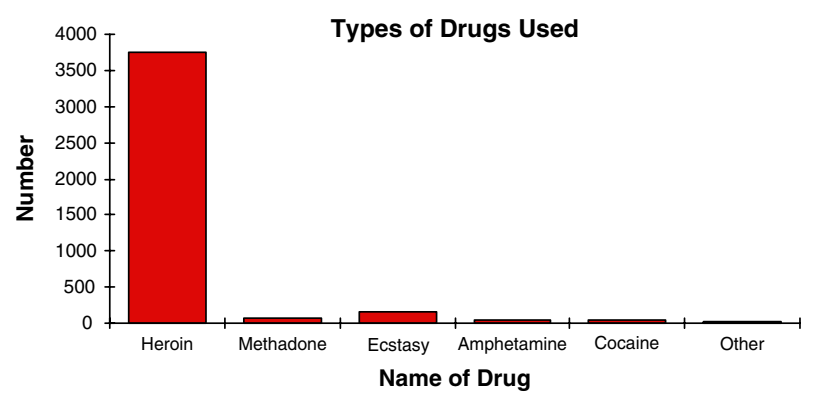

Fig. 1 Illicit drug use and related criminal activity of total arrests: 1996 (from Keogh 1997, p. 47) 
The introduction of the methadone protocol in this context was seen as a pragmatic success, albeit one that was necessarily covert in process. GPs had no role in the initial services, and the psychiatric services saw no role for them, stating that they were "not in favour of the treatment by GPs of drug addicts" (The Psychiatric Services 1984). Not surprisingly, many GPs were wary of involvement with drug users. However, a small group felt that they could not ignore the problem in their areas, and they put forward the view that MMT at the primary care level was legitimate and "evidence based practice" (Irish College of General Practitioners [ICGP] 1992). A formal protocol for methadone prescribing by GPs was published in 1993 (Department of Health 1992), and the number of GPs prescribing Methadone grew steadily over the next few years, tracking the explosion of heroin use in the capital. By the late 1990s, this growth produced some concerns over the relative ease of Methadone prescriptions. Thus, in 1997, the Irish College of General Practitioners was involved in producing guidelines for its members and updating the methadone protocol, and this was given statutory authority in 1998 through amended legislation. While both the statutory health agency and the ICGP urged its members to treat drug users in their localities, in practice, this legislation actually restricted the number of GPs prescribing methadone.

During the 1980s and 1990s, then, Irish psychiatry was keen not to be left behind on the treatment of drug abuse, but it also failed to articulate an obvious rationale for its leading role in the treatment of addiction. This hesitancy of Irish psychiatry to see heroin users as a logical market for its services occurs, despite the fact that the final stages of deinstitutionalisation in the Republic of Ireland were completed during what Butler (2002) has rightly seen as a second-wave intensification of heroin use in specific neighbourhoods in Dublin - and, further, the fact that the manifesto for the deinstituionalisation of mental hospitals in Ireland, Planning for the Future, charted out, at least in an off-hand way, a leading role for community psychiatry in drug treatment (The Psychiatric Services 1984; see also Department of Health 1992). Thus, the fact that Irish psychiatry remained in its institutionalised setting for longer than many of its neighbours in Northwest Europe (see Saris 1994, 1996) could have been construed as an advantage in this respect. Similarly, the relative size of the in-patient populations up until the late 1980s in many places, along with Irish psychiatry's relatively high use of the more severe diagnostic categories, could have presaged a willingness to deal with severe cases of substance abuse, such as heroin addiction, within an in-patient setting. At the very least, there was both a lot of spare capacity in the system and something like an ideological charter as to where this capacity could be directed at about the time that a moral panic swept Irish society about a problem in which psychiatry could legitimately have claimed some competence.

Yet, for the most part, this (seeming) comparative advantage of institutional psychiatry for such services was not developed. Instead, the main "medical" treatment option for heroin abuse in Ireland has been and remains MMT, administered predominantly through GPs and secondary/tertiary care centres, generally with ostensible psychiatric leadership but, in reality, only spotty psychiatric back-up. The number of Irish consultant psychiatrists specializing in drug abuse, for example, can be counted on one hand, despite the acknowledgement 
that Dublin, in particular, has a huge heroin issue. Some of the main centres of "treatment" in Ireland, furthermore, such as the Coolmine Therapeutic Community, are more or less anti-psychiatric in their orientation. While this eclectic mix of drug abuse interventions can be found in most countries, my reading of the literature, supported by the sense of most psychiatrists I know, is that Ireland presents one of the least psychiatrically influenced national addiction treatment establishments in Europe.

\section{The Historical Moment}

The social-historical context of these developments is a complex one. In this section, I rely on the work of Paul Quigley and some of my previous work (Saris and Bartley 1999a, b). Over the past 30 years, opiate injecting has presented a serious public health threat, one that is highly concentrated in so-called "socially excluded" Dublin inner-city communities (O'Gorman 1998). At the same time, it is something of a misnomer to refer to a "heroin" or even an "opiate" problem, as, generally speaking, we see multi-substance misuse (Smyth et al. 2000), involving opiates, benzodiazepines, cannabis, alcohol, often antidepressants and, increasingly, cocaine.

The advent of the HIV epidemic changed some thinking on the highly centralised Irish model, with a single medical agency operating, to a brief detox followed by abstinence model (Butler 1991), what we might call an acute psychiatric vision of the problem. By the late 1980s, though, it was clear that addicts were continuing to seek methadone and other prescribed opiates covertly from GPs, leading sometimes to inappropriate, dangerous or discreditable patterns of methadone use. In response to serious concerns about HIV, though, officially sanctioned methadone maintenance and needle exchange programmes were gradually introduced from the late 1980s, and responsibility for the development of new treatment facilities was devolved to health boards (Quigley n.d.).

The sorts of multiple deprivations becoming associated with heroin use in Dublin by the 1990s were synergistically exacerbating one another and, in most respects, impervious to easy solutions. Indeed, the closer one looked at some of these lives, the more difficult individuals, it became to pick out one (even "chemical") problem.

A (interviewer): And where were ye getting the tablet from ... buying them on the street?

$M$ (user): Buying them ya. So, say we got fourteen [Rohypnol] we'd go seven and seven when we err ... smoking [heroin], but he was getting that extra bit stoned then now that he was injecting [heroin], that he was giving me his tablets, so that was keeping me going. So, then we got a doctor, and we were getting methadone off the doctor. The type of doctor we got, he was an old man and he was just prescribing, prescribing, prescribing. So, we used to go to him, two, three times a week letting on our bottles were after smashing and you know telling him the whole story and the whole lot. So, we didn't have to really shoplift anymore then because we were selling the methadone to pay for the heroin and that.... So .... 
[my partner] was getting more stoned. The way he was getting stoned with the injections was different to the way he was getting stoned on the ... smoking.

I couldn't stand ... the whole needle thing, I just, I don't know...

Without getting into any models of poly-drug use, ${ }^{5}$ my point is that the issues involved in the lives of this couple are only slightly covered by the term "heroin addiction."

The link between severe poverty and opiate injection had been identified at an early stage of Dublin's widespread use of heroin (Dean et al. 1983; Department of Health 1993), but it was not until 1996 that a Ministerial Task Force publicly accepted the centrality of this relationship. By the mid-1990s, it was also evident that heroin and criminality were linked: or, perhaps more accurately, the drug of choice for most prisoners was heroin.

Demand reduction measures, including treatment facilities and local drugs task forces, were selectively aimed at communities where social exclusion was seen to be most severe and intractable. This was part of a broad refiguring of poverty and structural violence in Irish society under the aegis of spatial thinking and technocratic "planning," which many scholars (see Saris and Bartley 2002a, b) have examined from a variety of angles. Whatever the intention of the makers of this paradigm, income inequalities widened considerably during this period, and heroin use became normalised, then institutionalised, in the very neighbourhoods to which resources were directed. The practical expression of this policy with respect to heroin use was the building and staffing of new statutory-based methadone clinics in disadvantaged neighbourhoods. Not surprisingly, such "problem-directed resources," in the absence of nearly any other services and in the face of the continuing worsening of the problem in the 1990s, caused a lot of political friction (Saris and Bartley 2002a, b).

On 1 October 1998, The Misuse of Drugs (Supervision of Prescription and Supply of Methadone) Regulations came into effect in Ireland. This law was the result of nearly a decade of policy papers and legal developments. The new regulations restricted the number of GPs who could prescribe methadone in their practices. It also provided, for the first time, a Central Treatment List, which, as I have detailed above, to this day, remains the only Treatment List Benchmark in the Republic of Ireland. By 2000, there were slightly under 5,000 people on this register, and it is currently hovering around 7,000. Meanwhile, nearly all prevalence estimates of opiate use have pointed to a more or less stable number of addicts since the late 1990s (between 12,000 and 14,000) (Kelly 2004).

The policy and legal frameworks laid down in the 1990s also developed the treatment infrastructure for substance abuse. These were guided by the desire to place methadone within the most affected communities, to interrupt as much as possible the transmission of HIV and to deal with the issue of criminality, which emerged early on as being very strongly connected to heroin. Methadone, then, was inserted into a complex.

\footnotetext{
5 The issue of co-use is, of course, recognised by Irish practitioners, yet policymakers tend to treat "heroin users" as very faithful to their drug of choice (see, e.g., Rooney et al. 1999).
} 


\section{The Broader Context of Heroin Abuse}

The emergence of heroin as a significant issue in Ireland, specifically in the capital, Dublin, was coterminus with the mass loss of manufacturing jobs and the start of an extended economic crisis for the country as a whole. Heroin emerged as a significant problem in the poorest, most socially excluded neighbourhoods in the capital, especially amongst younger males. Moral panics about IV drug use swept through more "respectable" parts of the society in the early 1980s, but the problem had quieted down by the middle part of the decade. It reemerged again in the early 1990s, O'Hare and O'Brien (1993) reporting that more than 2,000 people were being treated in an emerging treatment system that was still largely informal, a 10fold increase since 1980 .

The intensification of heroin use in the late $80 \mathrm{~s}$ and early $90 \mathrm{~s}$, however, encountered an Irish society that was very much changing. By 1990, the fear of HIV in the injecting population had made at least some harm-reduction models more palatable to Irish policymakers and health officials. In many respects, the condom machine is a better social index to which to connect MMT than abstract medical reasoning, not as the success of the "permissive society" and the "liberal consensus" still bemoaned by Irish conservatives, but as the result of Irish policymakers and medical establishment figures having no other tool with which to address a serious public health concern. Folks knew that there was a combination of unprotected sex (large numbers of Irish women taking the ferry to Britain for abortion services), a growing IV drug use problem (based in neighbourhoods at least semi-opaque to the gaze of the state [Saris 1999b]) and a significant, if not actually thriving, sex industry.

Ironically, aspects of the success of these new programmes fed middle-class fears about the contagions borne in the bodies of junkies, which, in turn, fed aspects of local dystopias (Saris and Bartley 1999a, b, 2002a). The unintended consequence of the legitimate worries about HIV/AIDS with respect to IV use, for example, did not reduce the supply of heroin, or the population who might be interested in trying it; instead it made smoking heroin a much more common exercise than had hitherto been the case. In practice, this change ruptured the close connection between heroin use and injection, which was, ironically, one of the main pillars upon which its local stigma rested in many neighbourhoods. At about the same time, the "dirty syringe" became both icon and metonym of a serious social problem, and of course, its use as a means of establishing dominance during robberies became obvious (Saris 1991; Saris and Bartley 2002a).

To put it simply, heroin became increasingly associated with locally novel settings and people. From its historical position as something of a specialty drug, generally at the end of a chain of other substances, it became much more socially visible and physically available. At the same time, the age at which heroin could potentially be used plummeted. An early change, for example, was the marketing of heroin with Ecstasy (Gervin et al. 2001), ostensibly as a means of "coming down" from a weekend of raves (see also O'Toole 2005). This change in the way that the drug was supplied might have been as much an indication of just how much heroin was available at this time than any coordinated plan on the part of various dealers. 
Very quickly, though, this "mainstreaming" process became much more direct and strategic, with free bags of heroin becoming available to any new and/or young faces at better-known drugs distribution points in the city. In this way, heroin became much more visible to, conceivable for and useable by young people in by the mid-1990s in comparison to only a few years before (Saris and Bartley 1999a).

\section{Social Policy and Psychiatry in Ireland}

On the one hand, this accretion of policies, often exported from the outside, resembles other aspects of Irish social planning, which has often been criticised as being reactive and imitative (e.g., National Economic and Social Council 1995). The public health authority for this area of Ireland largely followed imported abstinence-directed models, and no serious debate took place about the relative success of legal-political frameworks around drugs and drug use in different places. Others could read the Irish case as a process of slow modernisation, as addiction was freed from a moral discourse and certain harm-reduction models become more imaginable to medical and technocratic elites. I believe, though, that confining our discussion to different versions of "therapy" and "policy" misses larger issues contextualising problems that are at once, medical, social, behavioural and legal. On the one hand, localising treatment, which MMT considerably facilitated, dovetailed nicely with new ways that poverty was being imagined in Ireland. It also allowed, to some extent, the management of the spatial movement of "junkies" in the built environment while providing a tool to change at least some behaviour. To be sure, fear of HIV motivated some important changes in policy, but this fear was also exploitable by the truly wretched through robberies at syringe point, which were disturbingly common by the mid-1990s in Dublin. MMT, then, could easily be seen to serve a variety of interests, more powerful than either psychiatry or its critics.

By the mid-1990s, moreover, new models of governance had created a dense para-state web around certain "socially excluded" communities in Ireland in the form of various Local Development Groups (see Saris and Bartley 2002b), but the new heroin problem added extra layers of Task Forces and Community Drugs Teams, which became some of the most stable and best-funded local organisations in these neighborhoods. In this sense, they added to the remarkable presence of the state in the lives of populations who were told at the same time to expect less and less of the state in the form of various welfare benefits and other entitlements. These groups provided a powerful institutional way of resisting changes to the treatment protocol. They also provided one of the few reasonable expectations of employment for someone only recently clean, that is, as an addiction counsellor in a seemingly ever-expanding cult of affliction.

\section{Conclusion}

The idea of "community" is central here: distressed communities create junkies; heroin is a problem for certain communities; junkies are their own community at 
other times; psychiatry is committed to provide community services, and state regulation and funding appear to flow preferentially for at least certain areas and populations through community groups rather than "regular politics." In a certain sense, policymakers and health professionals form yet another "community." Thus, while psychiatric knowledge and techniques flowed into "the community" in Ireland, they did so at a historical moment when "the community" emerged as a central term in a wide variety of other discourses, especially discourses moulding understandings of power and inequalities (Saris and Bartley 2002a). Methadone serves many of these definitions of community with respect to the management of opiate abuse, but especially their more inspectorial versions. From its dosing schedule, to its ability to be tracked, to the way it lends itself to the creation of a central list, methadone provides a means of imagining populations and problems that flow easily through the new topography of governance that stresses internal dynamics in the development and perpetuation of what look at first glance to be structural problems, a topography that had already rearranged institutional psychiatry in Ireland. "Community" is an important signpost on this new landscape, one that has held onto its positive valence, despite some of the seeming perverse effects in its wake. The success of this term, it seems to me, is precisely what requires further scholarly work.

We are confronted, then, by the limits of explanations, based exclusively in pharmacology, culture, social policy or politics. Methadone emerged as a pharmacological work-around for an unfortunate, but ideologically deracinated, impulse from our "emotional dark ages" (Berger 1964, p. 409)—an insatiable appetite, based in either "predisposition" or poor choices that at some point could not be undone (see also Bergschmidt 2004). It was (and perhaps remains) the most successful attempt to date to "disengage behavior from metaphysics" (Kreek; quoted in Shell 2003, p. 71). Dole and Nyswander's theorising methadone, then, helps to establish the modern moment of what we might call psycho-social pharmacology. In this discourse, our worries about methadone or prozac or XXX are based in an irrational attachment to the organ in which the lesion resides, the brain, as opposed to the more "objective" way that we view, say, the malfunctioning of our pancreas.

The problem, it seems to me, has less to do with philosophy than context. Competing discourse, the historical moment, varying technical expertises and different political environments all play a part in pharmacology. Psycho-pharmacologists have actually conducted some elegant experiments demonstrating at least aspects of this assertion (Morgan et al. 2002). ${ }^{6}$ A call for a radical socialisation of pharmacology and greater understanding of brain chemistry in social science is radically overdue, but alongside this must be a close analysis of the institutional

\footnotetext{
${ }^{6}$ In 2000-2001, Morgan et al. (2002), at several sites in the United States, gave cocaine to macaques. The macaques, while raised individually, were allowed to form social groups, complete with dominance hierarchies. Cocaine was offered only after such hierarchies are established. While all the monkeys tried cocaine, only the ones on the bottom of the hierarchies self-administered as often as possible (the closest model that folks who torment monkeys have to what humans call "addiction"). Furthermore, these monkeys showed a wide variance in positron emission topography (PET) scans of their brains, with dominant ones showing higher numbers, and activity levels, of $\mathrm{D}_{2}$ receptors, which are implicated in the brain's management of pleasure and aversion. Their conclusion: that brain chemistry, individual history, pharmacological action and social dynamics are difficult, if not impossible, to disaggregate.
} 
structures through which psychiatric knowledges and practices are imported and localised.

Acknowledgements Versions of this paper were delivered to the session "Historical and Contemporary Domains of Psychiatric Practice: From Center to Periphery" at the 2005 American Anthropological Association Annual Meeting, Washington, DC, and the Anthropology Seminar at Maynooth (Autumn 2005). I would like to thank participants at both these sessions for their very helpful comments, particularly Janis Jenkins, who served as discussant at the AAA session. I would like also to thank Emma Heffernan, Ruth McLoughlin and Fiona O'Reilley, who read and commented on earlier versions of this work. Different parts of this research were funded by the Ballyfermot Area Partnership and Ballyfermot Drugs Task Force (1999), The Katherine Howard Foundation (1997-1999), and the National Institute for Regional and Spatial Analysis (NIRSA), which provided me a teaching buyout in the Spring of 2003. This support facilitated this research. The National Advisory Committee on Drugs funded the work for Saris and Comiskey (2003) (see www.nacd.ie/activities/network_analysis.html). See also Comiskey et al. (2007).

\section{References}

Agar, Michael

1971 Ripping and Running: A Formal Ethnography of Urban Heroin Addicts. New York: Seminar Press.

Agar, Michael, and Heather Schacht Reisinger

2001 Open Marginality: Heroin Epidemics in Different Groups. Journal of Drug Issues 31(3): 729_ 746.

2002a A Tale of Two Policies: The French Connection, Methadone, and Heroin Epidemics. Culture, Medicine and Psychiatry 26: 371-396.

2002b A Heroin Epidemic at the Intersection of Histories: The 1960s Epidemic among African Americans in Baltimore. Medical Anthropology 21: 189-230.

Berger, Frank

1964 The Tranquilizer Decade. Journal of Neuropsychiatry 5: 403-410.

Bergschmidt, Viktoria B.

2004 Pleasure, Power and Dangerous Substances: Applying Foucault to the Study of 'Heroin Dependence' in Germany. Anthropology \& Medicine 11(1): 59-73.

Biskind, Peter

1975 Methadone: An American Way of Dealing the Big Fix Jump Cut. A Review of Contemporary Media 5: 9-11.

Burroughs, William

2005 Naked Lunch [the restored text]. New York: Harper.

Butler, Shane

1991 Drug Problems and Drug Policies in Ireland: A Quarter of a Century Reviewed. Administration 39: $210-233$

2002 The Making of the Methadone Protocol: The Irish System. Drugs: Education, Prevention and Policy 9(4): 310-324.

Comiskey, Catherine, A. Jamie Saris, and Julian Pugh

2007 Estimating the Prevalence of Opiate Use in Ireland and the Implications for the Criminal Justice System. Probation Journal 54(1): 22-35.

Courtwright, D.T.

1997 The Prepared Mind: Marie Nyswander, Methadone Maintenance, and the Metabolic Theory of Addiction. Addiction 92(3): 257-265.

Cullen, W., G. Bury, J. Barry, and F. O'Kelly

2000 Drug Users Attending General Practice in Eastern Regional Health Authority (ERHA) Area. Irish Medical Journal 93(7): 214-217.

Dean, G., J. Bradshaw, and P. Lavelle

1983 Drug Misuse in Ireland 1982-1983- Investigation on a North Central Dublin Area and in Galway, Sligo and Cork. Dublin: The Medico-Social Research Board. 
Department of Health

1992 Green Paper on Mental Health. Dublin: The Stationery Office.

1993 Report of the Expert Group on the Establishment of a Protocol for the Prescribing of Methadone. Dublin: Department of Health.

De Quincey, Thomas

1822 Confessions of an English Opium Eater. Available at: http://supervert.com/elibrary/thomas de_quincey.

Devereux, Paul

1997 The Long Trip: A Prehistory of Psychodelia. New York: Penguin Books.

Dole, Vincent

1991 Interim Methadone Clinics: An Undervalued Approach. American Journal of Public Health 18(9): 1111-1112.

1996 Interview with Dr. Vincent Dole, M.D. Methadone: The Next 30 Years? Addiction Treatment Forum V (Winter).

Dole, V.P., and M.E. Nyswander

1967 Heroin Addiction-A Metabolic Disease. Archives of Internal Medicine 120: 19-24.

1976 Methadone Maintenance Treatment: A Ten-Year Perspective. Journal of the American Medical Association 235: 2117-2119.

Drugs in Focus

2002 Key Role of Substitution in Drug Treatment. Available at: http://www.emcdda.org.

Eisenberg, Leon

2000 Is Psychiatry More Mindful or Brainier Than It Was a Decade Ago. British Journal of Psychiatry 176: $1-5$.

Fernandez, James

1986 Persuasions and Performances: The Play of Tropes in Culture. Bloomington: Indiana University Press.

Gervin, Maurice, Rita Hughes, Lindsay Bamford, Bobby P. Smyth, and Eamon Keenan

2001 Heroin Smoking by "Chasing The Dragon" in Young Opiate Users in Ireland: Stability and Associations with Use to "Come Down" Off "Ecstasy". Journal of Substance Abuse Treatment 20: 297-300.

Gossop, M., J. Marsden, D. Stewart, P. Lehmann, C. Edwards, A. Wilson, and G. Segar

1998 Substance Use, Health and Social Problems of Service Users at 54 Drug Treatment Agencies. Intake Data From the National Treatment Outcome Research Study.

Irish College of General Practitioners

1992 Submission on the Green Paper on Mental Health. Dublin.

Kelly, Alan

2004 Opiate Use in Ireland 2000-2001. A 3-Source Capture Recapture Study of the Prevalence of Opiate Use in Ireland. Available at: http://www.nacd.ie/publications/prevalence _ opiateuseinireland.html.

Keogh, Eamonn,

1997 Illicit Drug Use \& Related Criminal Activity in the Dublin Metropolitan Area. An Garda Siochana. Dublin: Garda Research Unit.

Lakoff, Andrew

2006 Pharmaceutical Reason: Knowledge and Value in Global Psychiatry. Cambridge, UK: Cambridge University Press.

Luhrmann, Tanya M.

2000 Of Two Minds: The Growing Disorder in American Psychiatry. New York: Alfred A. Knopf.

Marlowe, Ann

1999 How to Stop Time: Heroin from A-Z. New York: Virago Books.

Marsch, L.A.

1998 The Efficacy of Methadone Maintenance Interventions in Reducing Illicit Opiate Use, HIV Risk Behaviour and Criminality: A Meta-Analysis. Addiction 93: 515-532.

Metzl, Jonathan

2003 Prozac on the Couch. Durham, NC: Duke University Press.

Morgan, D., K. Grant, H. Gage, R. Mach, J. Kaplan, O. Prioleau, S. Nader, N. Buchheimer,

R. Ehrenkaufer, and M. Nader

2002 Social Dominance in Monkeys: Dopamine D2 Receptors and Cocaine Self- Administration'. Nature Neuroscience 5: 169-174. 
National Economic and Social Council

1995 New Approaches to Rural Development. Dublin: Government Paper Office.

Negroponte, Michael

2005 Methodonia. http://www.hbo.com/docs/programs/methadonia/index.html.

O'Gorman, A.

1998 Illicit Drug Use in Ireland: An Overview of the Problem and Policy Responses. Journal of Drug Issues 28(1): 155-166.

O'Hare, A., and M. O'Brien

1993 Treated Drug Misuse in the Greater Dublin Area 1991. Dublin: Health Research Board.

O'Reilly, Fiona, Emily Reaper, and Tom Redmond

2005 We are People Too: Views of Drug Users on Health Services. Dublin: Uisce.

O'Toole, Julie

2005 Heroin: A True Story of Drug Addiction, Hope and Triumph. Dunshaughlin, Meath, Ireland: Maverick House.

Quigley, Paul

n.d. Family and Community Burdens of Addiction: Casemix Analysis at a New Community-Based Methadone Treatment Service.

Rieff, Philip

1987 The Triumph of the Therapeutic: Uses of Faith After Freud. Chicago: University of Chicago Press.

Rooney, S., G. Kelly, L. Bamford, D. Sloan, and J.J. O’Connor

1999 Co-Abuse of Opiates and Benzodiazepines. Irish Journal Medical Science 168(1): 36-41.

Sadowsky, Jonathan

1999 Imperial Bedlam: Institutions of Madness in Colonial Southwest Nigeria. Berkeley: University of California Press.

Saris, A. Jamie

1994 The Proper Place For Lunatics: Person, Asylum, and History in a Rural Irish Community. Unpublished PhD dissertation, The University of Chicago.

1996 Mad Kings, Proper Houses, and an Asylum in Rural Ireland. American Anthropologist 98(3): 539-554.

1997 The Asylum in Ireland: A Brief Institutional History and Some Local Effects. In The Sociology of Health and Illness in Ireland, Cleary. Anne Tracy and Margaret P. Tracy, eds., pp. 208-223. Dublin: University College Dublin Press.

1999 Producing Persons and Developing Institutions in Rural Ireland. American Ethnologist 26(3): 690-710.

Saris, A. Jamie, and Brendan Bartley

1999a [with Brendan Bartley and Field Researchers] Final Report: Life Histories of Drug Users and Drug Use in the Community in Ballyfermot and Cherry Orchard. Submitted to the Ballyfermot Area Partnership. Maynooth, Ireland. 1 September.

1999b [with Brendan Bartley and Field Researchers] Final Report: Community Policing in Ballyfermot and Cherry Orchard. Submitted to the Ballyfermot Area Partnership. Maynooth, Ireland. 1 September.

2002a The Arts of Memory: Icon and Structural Violence in a Dublin 'Underclass' Housing Estate. Anthropology Today 18(4): 14-19.

2002b Culture and the State: Institutionalising 'the Underclass' in the New Ireland. City 6(2): 167191.

Saris, A. Jamie, and Catherine Comiskey (with Field Researchers)

2003 Interim Report: A Network Analysis Study, With An In-Depth Interview Component. National Advisory Committee on Drugs. 60 pp. Submitted 1 December. Dublin. http://www.nacd.ie/ activities/network_analysis.html).

Shell, Ellen

2003 Fat Wars: The Inside Story of the Obesity Industry. New York: Atlantic Books.

Smyth, B., M. O’Brien, and J. Barry

2000 Trends in Treated Drug Misuse in Dublin: The Emergence of Chasing the Dragon. Addiction 95(8): 1217-1223.

Steentoft, A., B. Teige, P. Holmgren, E. Vuori, J. Kristinsson, A.C. Hansen, G. Ceder, G. Wethe, and D. Rollmann

2006 Fatal Poisoning in Nordic Drug Addicts in 2002. Forensic Science International 160: 148-156. 
The Psychiatric Services

1984 The Psychiatric Services: Planning for the Future. Dublin: Stationary Office.

Woolverton, John

1983 Evangelical Protestanism and Alcoholism, 1933-1962: Episcopalian Samuel Shoemaker and Alcoholics Anonymous. Historical Magazine of the Protestant Episcopal Church. March:53-65.

Wortis, Joseph

1950 Soviet Psychiatry. Baltimore: Williams and Wilkins. 